\title{
Needle Stick Injuries among Health Care Workers in AL-Madinah AL-Munawara Governmental Hospitals in Saudi Arabia
}

\author{
Omar Audah Albeladi ${ }^{1}$, Sami saeed Almudaraa ${ }^{1}$, Asma Awwad Alqusibri ${ }^{1}$, Nader Moneer Alqerafi ${ }^{2}$, \\ Yazeed Saeed Alsenani ${ }^{3} \&$ Eman Elsayed Abd-Ellatif ${ }^{4}$ \\ ${ }^{1}$ Field Epidemiology Training Program, Ministry of health, Riyadh, Kingdom of Saudi Arabia \\ ${ }^{2}$ King Salman Medical city, Ministry of health, AL Madinah AL Munawara, Kingdom of Saudi Arabia \\ ${ }^{3}$ Academic of Family Med, AL Madinah AL Munawara, Kingdom of Saudi Arabia \\ ${ }^{4}$ Department of Public Health \& Community Medicine, Faculty of Medicine, Mansoura University, Egypt \\ Correspondence: Eman Elsayed Abd-Ellatif, Department of Public Health \& Community Medicine, Faculty of \\ Medicine, Mansoura University, Egypt.
}

Received: July 27, 2021 Accepted: September 5, 2021 Online Published: October 8, 2021

doi:10.5539/gjhs.v13n11p76 URL: https://doi.org/10.5539/gjhs.v13n11p76

\begin{abstract}
Background: Needle stick injuries are a dangerous occupational hazard that threatens health care workers with serious consequences in many cases. Because of inadequate reporting of these incidents, the true magnitude of the problem is unknown. The study's aim was to investigate the epidemiology of needle stick injuries (NSIs) among health care workers in Al Madinah Al Munawara, Saudi Arabia.
\end{abstract}

Methods: A representative sample of health care workers $(n=268)$ were randomly selected from emergency departments of three general hospitals in Al Madinah Al Munawara for a cross-sectional study, and 219 responded to a predesigned questionnaire reflecting exposure to NSI, reporting, post-exposure reactions, and knowledge about NSIs.

Results: Almost one third of the participating medical professionals $70(32 \%)$ had been exposed to stick injury during work. One half of the needles $(52.9 \%)$ were blood stained. Nurses are significantly more likely to have stick injury (38.6\%) followed by physicians (30.4\%) if compared to laboratory technicians (13.9\%) at the p-value of less than 0.05 . The main purposes during injuries were drawing blood sample $33(47.1 \%)$, injection 31 (44.3\%) and suturing $23(32.9 \%)$. Almost all injured personnel (97.1\%) cleaned the injury site immediately and thoroughly. Out of the injured personnel, $50(71.4 \%)$ reported the incident to authorities. A significantly higher proportion of physicians (91.3\%) achieved above average score if compared to both lab technicians $(72.2 \%)$ and nurses $(76.3 \%)$ at the p-value of less than 0.05 .

Conclusion: Occupational needle stick injuries are fairly common among health care workers at Al Madinah Al Munawara's governmental hospitals. In hospitals, deliberate efforts should be made to ensure adherence to safety guidelines governing needle stick injuries.

Keywords: emergency departments, public hospitals, health care workers, needle stick injuries, Saudi Arabia

\section{Introduction}

In recent decades, occupational exposure among healthcare workers (HCWs) has increased. HCWs are frequently exposed to medical sharp instruments (Huang et al., 2017). Needle stick injuries (NSIs) are one of the most common hazards for HCWs, particularly nurses (Tawil, 2016). Sharp injury occurs when a sharp object, such as a needle, penetrates the skin. There is a risk of infection transmission if the sharp instrument is contaminated with blood or bodily fluids (Deisenhammer, Radon, Nowak, \& Reichert, 2006). While up to twenty blood-borne pathogens (BBPs) can be transmitted through accidental injury, the most serious conditions are Human Immunodeficiency Virus (HIV), Hepatitis B virus (HBV), and Hepatitis C virus (HCV) (Zafar et al., 2009)

HCWs are at risk of contracting NSI from unsafe practices such as needle recapping, manipulating used needles such as bending, breaking, and cutting hypodermic needles, and passing needles from one HCW to another. The risk of NSI exposure by HCWs varies depending on the hospital department and the type of procedure (Muralidhar, Singh, Jain, Malhotra, \& Bala, 2010). 
According to the World Health Organization (WHO), approximately 3 million health care workers out of 35 million suffer from NSIs each year. Two million of those injuries were HBV-infected, 0.9 million were HCV-infected, and 170,000 were HIV-infected. More than $90 \%$ of these infections occur in developing countries (Bouya et al., 2020). According to the WHO, sharps exposure in the workplace accounts for $40 \%$ of $\mathrm{HBV}$ and HCV infection and $2 \%-3 \%$ of HIV infections among HCWs (Kelen et al., 1988).

Following NSI, the risk of infection transmission from infected patients to $\mathrm{HCW}$ is $3-10 \%$ for hepatitis $\mathrm{B}, 3 \%$ for hepatitis C, and $0.3 \%$ for HIV (Wilburn \& Eijkemans, 2004). In developing countries, 40-60\% of HBV infection among HCWs was attributed to occupational hazard while in developed countries the attributed fraction was less than $10 \%$ due to HBV vaccination coverage (Singhal, Bora, \& Singh, 2009). Adoption of safe injection practices in developed countries has reduced the risk of NSIs (Simonsen, Kane, Lloyd, Zaffran, \& Kane, 1999).

In developing countries, the situation is even worse than in developed countries. An increase in the incidence of NSIs, improper disposal of syringes and needles, and a low level of awareness and immunization of HCWs for blood-borne diseases are all possible causes. There are numerous factors that contribute to HCWs failing to report sharp injuries (Chowdhury et al., 2011). HCWs in developing countries, may believe that the injuries or source patients are low risk, they may be afraid of the diseases to which they may have been exposed. Furthermore, they may be concerned about job security, or they may be concerned about the extra paperwork and time involved in follow-up. Furthermore, they may be lacking in information and training regarding appropriate reporting procedures, or the reporting procedures themselves may be insufficient (Haiduven, Simpkins, Phillips, \& Stevens, 1999).

In Saudi Arabia, a retrospective cross-sectional study was conducted to examine the epidemiology of sharp injuries in HCWs working in a maternity and children's hospital over a six-month period. The findings of this study were, the incidence of injuries was highest among nurses, with most injuries occurring in operating and recovery rooms, particularly during the use of devices. The injuries occurred while wearing a single pair of gloves in the right hand, where almost all items were contaminated (Hashmi, Abu, Reesh, \& Indah, 2012).

Another study in Saudi Arabia compiled a needle stick and sharp-object injury report using data from 21 facilities from January 1st to March 31st, 2012. According to the report, nurses were the most injured, accounting for $66.4 \%$ of all injured workers, compared to $7.8 \%$ of physicians (Khabour, Al Ali, \& Mahallawi, 2018). The patient room (48.9\%), the emergency department (ER) (13.6\%), and the operating/recovery room $(11.5 \%)$ were the most common locations of NSIs. The sharp objects used in the injuries were contaminated in 89.3 percent of the cases. The majority of the injuries occurred during injections (17.9\%), venous blood sample drawing $(17.2 \%)$, and suturing (14.8\%). Injuries occurred 41.9 percent of the time while using the sharp items, while $18.6 \%$ were injured after use, but before disposal. The most common devices that caused injuries were disposable syringes (57.1\%), which were not "safety devices" $64.4 \%$ of the time. Hand injuries were the most common. When the staff wore a single pair of gloves, $68.3 \%$ of the sharps penetrated, $26.9 \%$ wore no gloves at all, and $4.8 \%$ wore a double pair of gloves, which may have reduced overall sharps penetration (Khabour et al., 2018).

In the Madinah region, there have been a few studies on needle stick injuries. The aim of this study is to determine the prevalence of NSI among HCWs in the ER departments of Madinah hospitals. This prevalence will guide Saudi ministry of health to implement prevention measures for safe use of sharp objects, raise awareness among health care workers, and emphasize the importance of reporting all cases of NSI.

\subsection{Aim of the Study}

To improve the preventive measure of occupational incidence of NSIs through addressing prevalence on NSI among HCWs in AL Madinah AL Munawara governmental hospitals in 2018.

\subsection{Objectives of the Study}

1) To estimate the prevalence of needle stick injuries among HCWs in the ER department of AL Madinah AL Munawara governmental hospitals in 2018.

2) To detect possible risk factors associated with NSI among HCWs in the ER department of Madinah Governmental hospitals in 2018.

\section{Material and Methods}

\subsection{Study Setting}

The study was carried out in five governmental hospitals run by the Ministry of Health (MOH) in Al-Madinah. The five governmental hospitals (King Fahad hospital and Ohud hospital in the west of the city, AlAnsar hospital and Maternity and Children hospital in the east of the city, and AlMeqat hospital in the south of the city) serve all 
Madinah region residents as well as pilgrims who visit Al-Madinah during the hajj season.

\subsection{Study Design}

Analytic cross-sectional study.

\subsection{Study Population}

HCWs who were currently working in the ER departments of MOH hospitals in Al-Madinah city. Different specialties (doctor, nurses, laboratory technicians) were considered eligible for inclusion in the study. The total population of the study was 530 people.

\section{Inclusion criteria:}

Doctors, nurses, laboratory technicians who are currently working in the ER departments in the selected hospitals. Both (male, female) and (Saudi, Non-Saudi) were involved.

\section{Exclusion criteria:}

Pharmacists, HCWs who are on vacation or come to the ER department for consultation from other departments and Any health worker who is working as office worker, were excluded.

\subsection{Sample Size}

Using Epi-info software version 7, sample size was estimated to be 223. Taking into account that the expected proportion of outcome (the rate of NSI among $\mathrm{HCWs}$ ) is $50 \%$, the worst accepted proportion is $\pm 5 \%$ and the level of confidence is $95 \%$.

\subsection{Sampling Technique}

Because the five hospitals in Al-Madinah city were so far apart, we chose only three of them to save time and effort. The three hospitals were chosen at random using simple random sampling. To ensure that each hospital was chosen at random and entirely by chance, we used five papers before selecting three of them manually by the researcher. The three chosen hospitals were Almeqat hospital, MCH hospital and Ohud hospital.

Following stratified random sampling with proportionate allocation based on the percentage of each occupational group (doctors, nurses, lab technicians), a simple random sample technique was used to select all participants in our study from an ER departments workers list using a computer program. $55 \mathrm{HCWs}$ were selected from Almeqat hospital, 102 from MCH hospital, and 62 from Ohud hospital.

\subsection{Tools of the Study}

For data collection, a pre-designed valid questionnaire was used. It was previously used in a study conducted in the Kingdom of Saudi Arabia. Personal communication with the author resulted in permission to use the questionnaire. (Khabour et al., 2018) The questionnaire collected demographic data (e.g., age, gender, marital status, work status), work-related factors (e.g., duration of working in the medical field, working hours, injuries per year, date and time of injury, etc.), and NSI experience. The questionnaire was distributed to HCWs in the ER department of the hospitals at every shift (morning, afternoon, and night) by five well-trained data collectors and recollected at the same time or within the next four days for nearly one-month data collection.

As part of the research protocol, a pilot study was carried out on $10 \%$ of the participants (28). Among HCWs in selected hospitals. The pilot study assisted in:

- Testing the participants' understanding of the questionnaire.

- Determine the amount of time required to complete the questionnaire.

- Describe the main study's actual situation.

The pilot study's findings were not included in the study.

\subsection{Data Analysis}

For the statistical analysis, the SPSS 23.0 software package was used. Response frequency distributions, cross-tabulations of individual and prevalence of needle stick injuries. The chi-square test was used to further investigate differences and/or associations. The level of significance was set at $\mathrm{p}<0.05$.

\subsection{Ethical Consideration}

Approval of the regional research committee, which adhered to the principles of the Declaration of Helsinki. An informed written consent was obtained from all participating physicians after clarification of the objectives, confidentiality of data, voluntary involvement in the study. Confidentiality of personal data will be granted to all 
participants. Patient privacy was the main ethical concern. Moreover, the study ensured that no personal information was revealed, and that the data obtained was used only for study purposes.

\section{Results}

The questionnaire was completed by 219 ( 98.2 percent) of the $223 \mathrm{HCWs}$ who were enrolled. According to the study design, $219 \mathrm{HCWs}$ were chosen randomly from three governmental hospitals. The objectives are to assess participants' exposure to needle stick injury (NSI) during their practice and its predictors, as well as their knowledge of NSI and infection risks.

The results are divided into three sections. The first one describes the study group's characteristics, as well as previous exposure to NSI and its associated factors. The second one represents behaviors of injured personnel after they have been injured. The third section assesses participants' knowledge of stick injury and related infections.

\subsection{Characteristics of the Study Group}

Out of all participants $(\mathrm{n}=219)$, females constituted $52.5 \%$, they were mostly either young aged (20-30 years) $(51.6 \%)$ or middle aged (31-40 years) $(36.5 \%)$. Almost half $(52.1 \%)$ were nurses, while the rest were either physicians $(31.5 \%)$ or lab technicians $(16.4 \%)$. Less than one half $(46.6 \%)$ were working in Maternal and Child hospital (MCH), 25.1\% in Almeqat hospital and 28.3 in Ohud hospital. Only $11.4 \%$ had experience for less than two years, slightly more than one third (34.7\%) had experience for $2-5$ years, while $26 \%$ had experience for ten years or longer (Table 1).

Table 1. Demographic characteristics of the study group $(\mathrm{n}=219)$

\begin{tabular}{llll}
\hline Variables & Categories & No. & \% \\
\hline \multirow{2}{*}{ Gender } & Male & 104 & 47.5 \\
& Female & 115 & 52.5 \\
\hline \multirow{3}{*}{ Age group } & $20-30$ years & 113 & 51.6 \\
& $31-40$ years & 80 & 36.5 \\
\hline \multirow{3}{*}{ Job } & $41+$ years & 26 & 11.9 \\
\hline \multirow{3}{*}{ Place of $\boldsymbol{w o r k}$} & Physician & 69 & 31.5 \\
& Lab technician & 36 & 16.4 \\
& Nurse & 114 & 52.1 \\
\hline \multirow{3}{*}{ Experience } & Almeqat & 55 & 25.1 \\
& MCH hospital & 102 & 46.6 \\
& Ohud hospital & 62 & 28.3 \\
\hline & $<2$ years & 25 & 11.4 \\
& $2-5$ years & 76 & 34.7 \\
& $6-9$ years & 61 & 27.9 \\
& $10+$ years & 57 & 26.0 \\
\hline
\end{tabular}

\subsection{Previous Exposure to Needle Stick Injury During Work}

Figure 1 shows that 70 of the participating medical professionals, or nearly one-third of the participants (32\%), had been exposed to NSIs at work. Out of them, as shown in Table 2, there was $41.4 \%$ who reported that they had been exposed to NSI 2-5 times along their practice, in addition to (2.9\%) where were injured 6-9 times. The injuries occurred in almost one half of them $(48.6 \%)$ in the past year. It was almost superficial $(67.2 \%)$, with only (5.7\%) that were deep; mainly in the right hand $(71.4 \%)$. One half of the needles $(52.9 \%)$ were blood stained, at time where the viral status of $50 \%$ of the patients was not known, and one patient was known as being positive for HBsAg, and two patients (2.9\%) were HIV positive. Meanwhile, on inquiry about the immunization status of the medical professionals at time of injury, Figure 2 displays that (10\%) were not immunized at all, and (18.6\%) were partially immunized against Hepatitis B, as they received only one or two doses.

The purposes and activities for using the sharp tools or instruments which resulted in brick injuries are shown in 
Figure 3 and Figure 4. The main purposes were drawing blood sample (47.1\%), injection (44.3\%) and suturing $(32.9 \%)$, and the main activities while injured were: while suturing $(32.9 \%)$, recapping $(32.9 \%)$, cannulation (25.7\%), venipuncture (18.6\%), cleaning (15.7\%) and disposal $(12.9 \%)$.

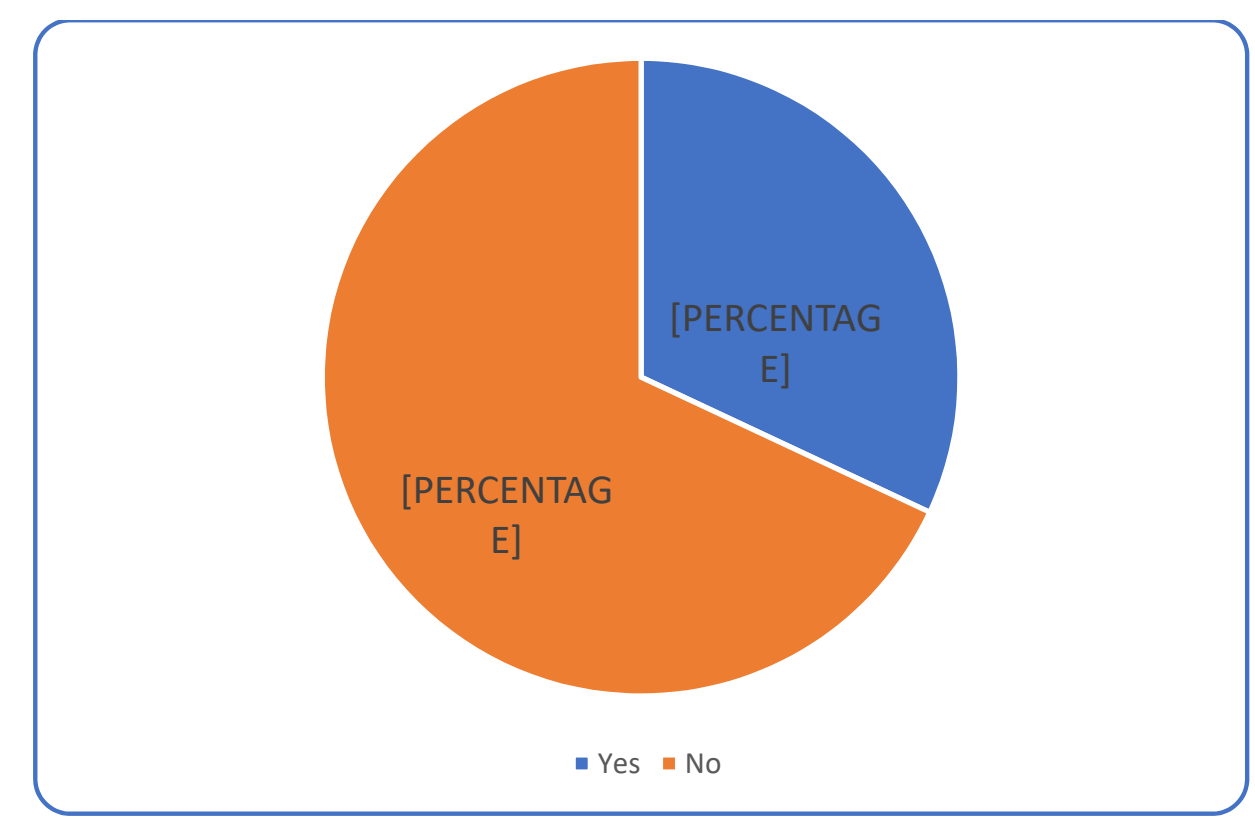

Figure 1. Previous experience of Needle Stick Injury during work

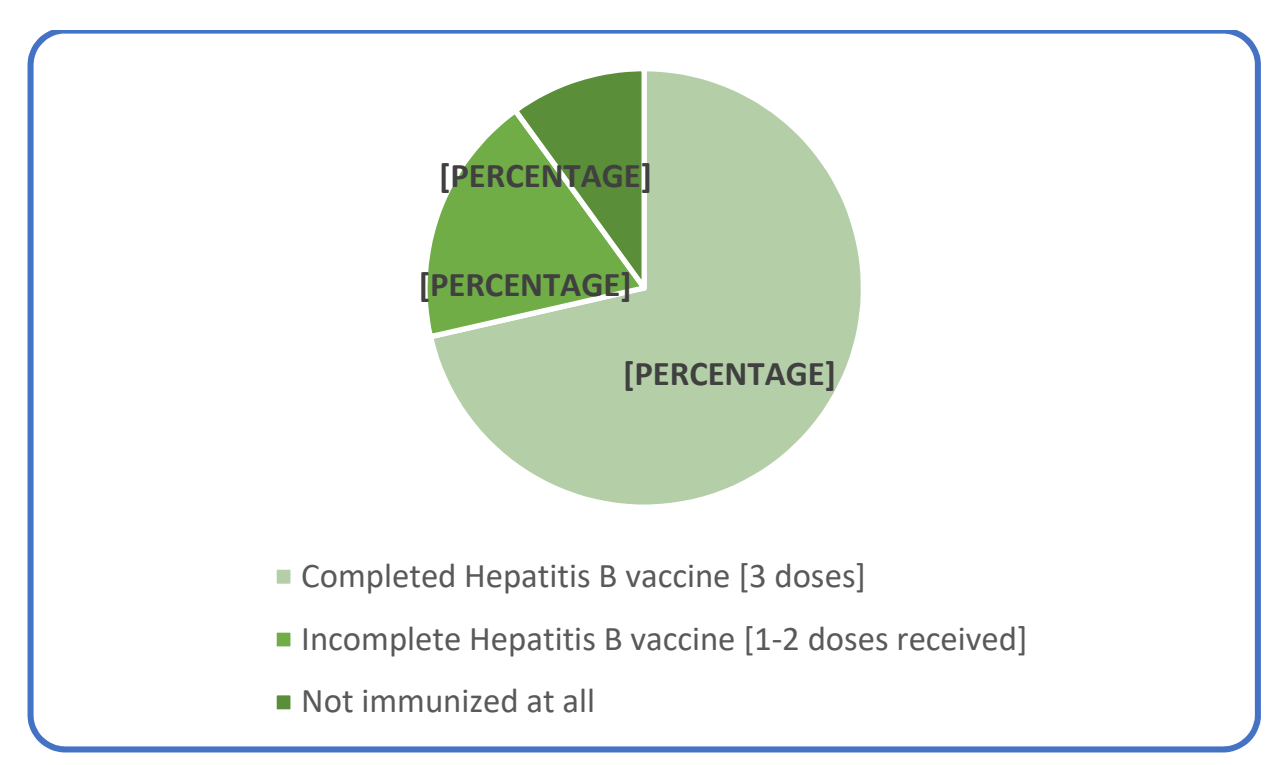

Figure 2. Immunization status at time of injury 
Table 2. Pattern of Needle Stick Injury $(n=70)$.

\begin{tabular}{|c|c|c|c|}
\hline Variables & Categories & No. & $\%$ \\
\hline \multirow{3}{*}{ Frequency } & Once & 39 & 55.7 \\
\hline & $2-5$ times & 29 & 41.4 \\
\hline & $\geq 6$ times & 2 & 2.9 \\
\hline \multirow{4}{*}{ Time of exposure } & Last year & 34 & 48.6 \\
\hline & Last $2-5$ years & 23 & 32.9 \\
\hline & Last 6-9 years & 8 & 11.4 \\
\hline & $10+$ years & 5 & 7.1 \\
\hline \multirow{3}{*}{ Nature of injury } & Superficial & 47 & 67.2 \\
\hline & Moderate & 19 & 27.1 \\
\hline & Deep & 4 & 5.7 \\
\hline \multirow{2}{*}{ Dominant hand } & Right handed & 50 & 71.4 \\
\hline & Left handed & 20 & 28.6 \\
\hline \multirow{4}{*}{ Bleeding } & Yes & 29 & 41.4 \\
\hline & No & 17 & 24.3 \\
\hline & Penetration of gloves & 17 & 24.3 \\
\hline & Cannot remember & 7 & 10.0 \\
\hline \multirow{2}{*}{ Nature of fluids in the needle } & Blood stained fluid in the needle & 37 & 52.9 \\
\hline & No blood stain & 33 & 47.1 \\
\hline \multirow{4}{*}{ Viral status of the patient } & Negative for all viruses & 32 & 45.7 \\
\hline & Not known & 35 & 50.0 \\
\hline & HBs Ag positive & 1 & 1.4 \\
\hline & HIV positive & 2 & 2.9 \\
\hline
\end{tabular}

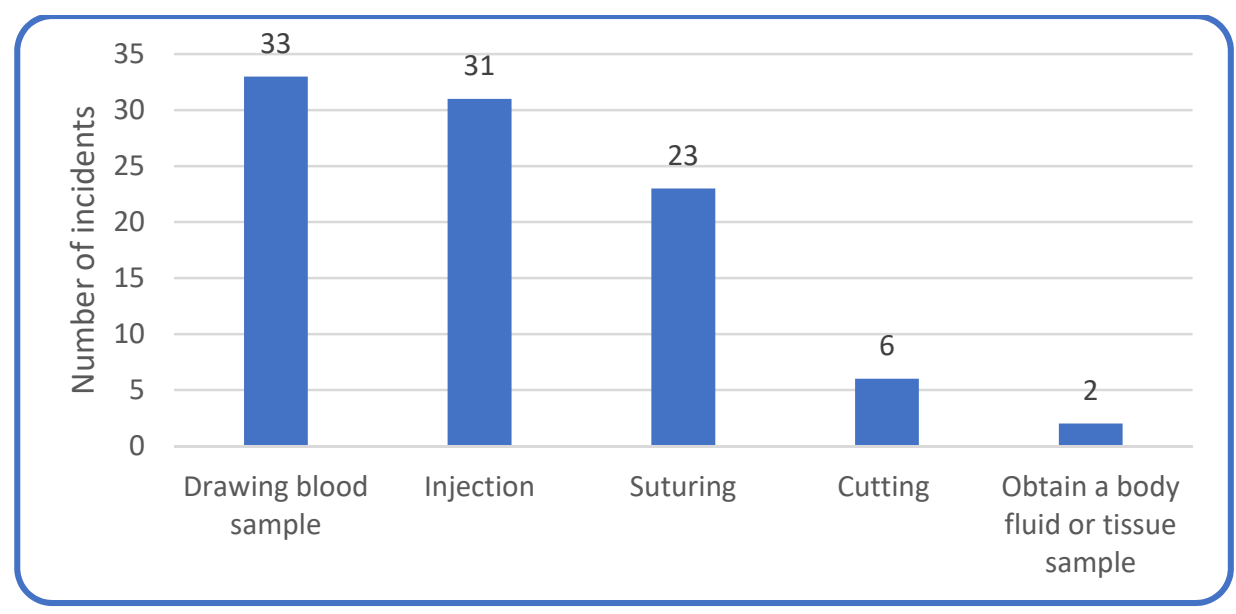

Figure 3. Purposes of using sharp items resulted in stick injury 


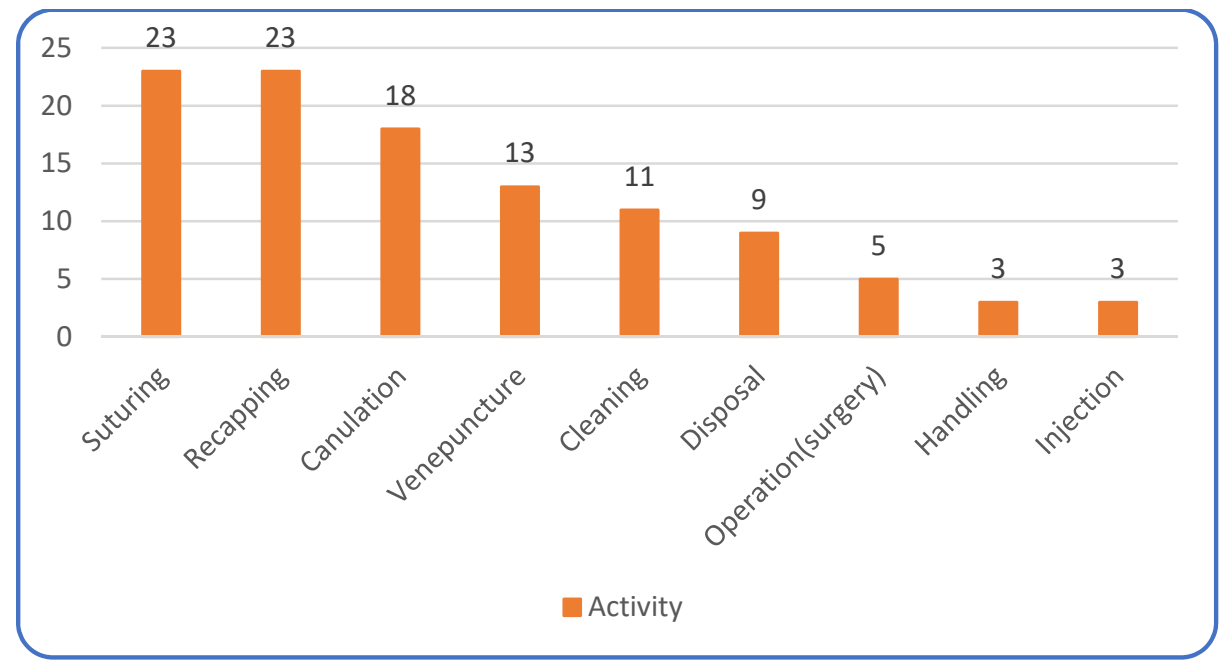

Figure 4. Activities resulted in stick injuries

\subsubsection{Factors Associated with Stick Injury during Work}

To determine factors increasing likelihood of stick injury during work, Table 3 shows that nurses are significantly more likely to have stick injury (38.6\%) followed by physicians (30.4\%) if compared to lab technicians (13.9\%) $\mathrm{p}<0.05$. On the other hand, it was found that although the brick injury occurred more frequently in female medical professionals than males $(34.8 \%$ vs $28.8 \%$ ), those aged 41 years or older $(34.6 \%)$, those who were working in Almeqat hospital (38.2\%) if compared to their colleagues in MCH hospital (32.4\%) and Ohud hospital (25.8\%), these differences are not statistically significant $p>0.05$. Also, it was observed that the likelihood of brick injury increases with increased year of experience, it ranged between $16 \%$ among those who had experience for less than two years and increased up to $37.7 \%$ in those who had experience for $6-9$ years and $35.1 \%$ in those who had experience for 10 years or longer, nevertheless, these differences are not statistically significant $\mathrm{p}>0.05$.

Table 3. Occurrence of stick injury according to characteristics of the study group

\begin{tabular}{|c|c|c|c|c|c|c|c|}
\hline \multirow{3}{*}{ Characteristics } & \multirow{3}{*}{ Categories } & \multicolumn{4}{|c|}{ Exposure to stick injury } & \multirow{3}{*}{$X^{2}$} & \multirow{3}{*}{$\mathbf{p}$} \\
\hline & & \multicolumn{2}{|l|}{ Yes } & \multicolumn{2}{|l|}{ No } & & \\
\hline & & No & $\%$ & No & $\%$ & & \\
\hline \multirow{2}{*}{ Gender } & Male & 30 & $28.8 \%$ & 74 & $71.2 \%$ & \multirow{2}{*}{0.885} & \multirow{2}{*}{0.347} \\
\hline & Female & 40 & $34.8 \%$ & 75 & $65.2 \%$ & & \\
\hline \multirow{3}{*}{ Age group } & 20-30 years & 36 & $31.9 \%$ & 77 & $68.1 \%$ & \multirow{3}{*}{0.103} & \multirow{3}{*}{0.950} \\
\hline & $31-40$ years & 25 & $31.2 \%$ & 55 & $68.8 \%$ & & \\
\hline & $41+$ years & 9 & $34.6 \%$ & 17 & $65.4 \%$ & & \\
\hline \multirow{3}{*}{$J o b$} & Physician & 21 & $30.4 \%$ & 48 & $69.6 \%$ & \multirow{3}{*}{7.789} & \multirow{3}{*}{$0.020^{* *}$} \\
\hline & Lab technician & 5 & $13.9 \%$ & 31 & $86.1 \%$ & & \\
\hline & Nurse & 44 & $38.6 \%$ & 70 & $61.4 \%$ & & \\
\hline \multirow{3}{*}{ Place of work } & Almeqat hospital & 21 & $38.2 \%$ & 34 & $61.8 \%$ & \multirow{3}{*}{2.066} & \multirow{3}{*}{0.356} \\
\hline & MCH hospital & 33 & $32.4 \%$ & 69 & $67.6 \%$ & & \\
\hline & Ohud hospital & 16 & $25.8 \%$ & 46 & $74.2 \%$ & & \\
\hline \multirow{4}{*}{ Experience } & $<2$ years & 4 & $16.0 \%$ & 21 & $84.0 \%$ & \multirow{4}{*}{4.211} & \multirow{4}{*}{0.240} \\
\hline & $2-5$ years & 23 & $30.3 \%$ & 53 & $69.7 \%$ & & \\
\hline & $6-9$ years & 23 & $37.7 \%$ & 38 & $62.3 \%$ & & \\
\hline & $10+$ years & 20 & $35.1 \%$ & 37 & $64.9 \%$ & & \\
\hline
\end{tabular}




\subsection{Reaction of the Injured Personnel after Stick Injury}

Table 4 shows that almost all injured personnel (97.1\%) cleaned the injury site immediately and thoroughly, while only $58.6 \%$ informed their manager/ head of department and equal percentage (58.6\%) who reported the occupational health department. Moreover, only $51.4 \%$ of the injured personnel indicated that they received any treatment (PEP, Booster dose Hepatitis B vaccine).

Regarding the overall number of injured personnel who reported to either the head of the department or the occupational health department 50(71.4\%),

Figure 5 shows that only $31(44.3 \%)$ of them reported the incident within one hour, and $16(22.9 \%)$ reported it within 24 hours and 3(4.3\%) reported after 24 hours.

Table 4. Reaction of the injured participants after injury $(\mathrm{n}=70)$.

\begin{tabular}{lcc}
\hline Reaction & No. & \% \\
\hline Clean injury site immediately and thoroughly & 68 & 97.1 \\
Informed manager/head & 41 & 58.6 \\
Reported occupational health department & 41 & 58.6 \\
Received any treatment (PEP, Booster dose Hepatitis B vaccine) & 36 & 51.4 \\
\hline
\end{tabular}

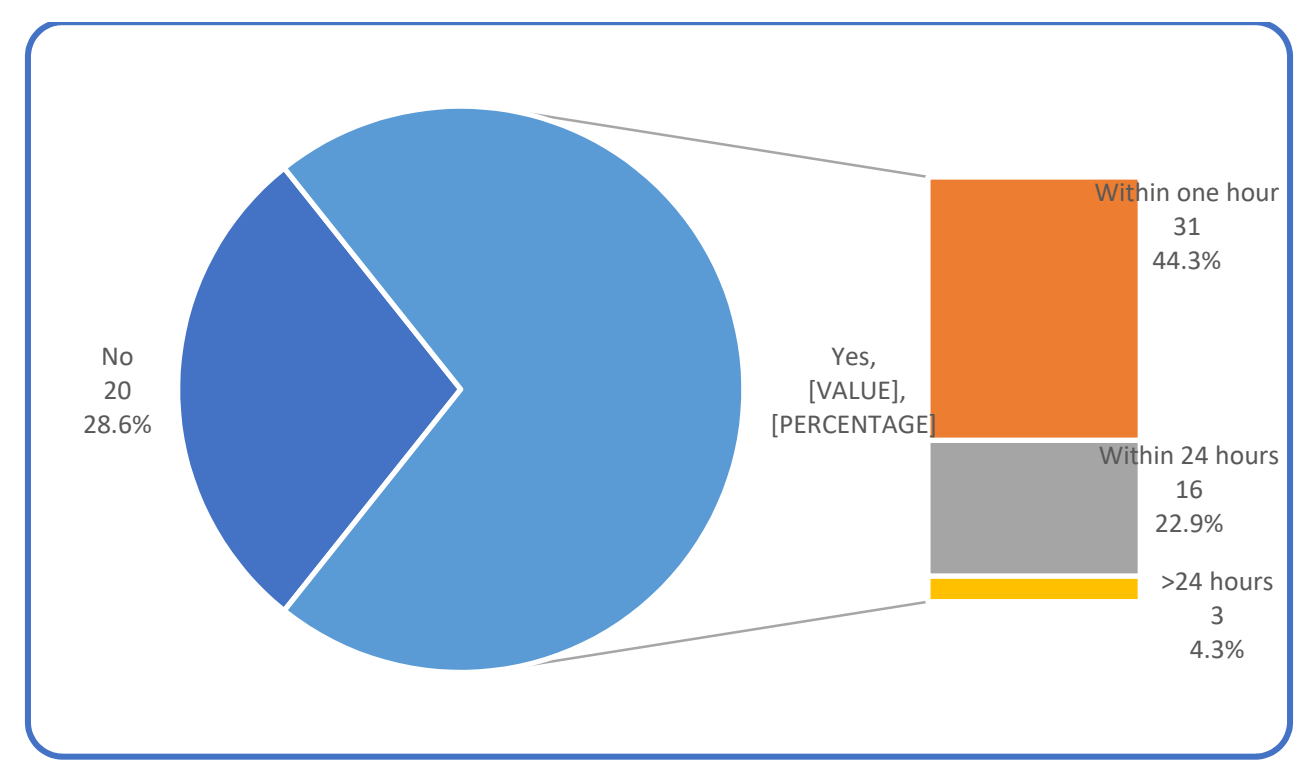

Figure 5. Reporting of the stick injury

\subsection{Knowledge of the Respondents about Stick Injury and Risks of Infection}

Table 5 describes the response of the medical professionals to the items reflecting their knowledge about prevention of stick injury and risks of infection, it shows that the overwhelming majority of them $(91.4 \%) \mathrm{knew}$ that the universal precaution decrease the risk of needle stick injuries, and the majority knew that needle stick injuries are preventable (85.7\%), and that the biggest reduction in transmission of blood-borne infections through unsafe injections can be achieved through eliminating unnecessary injection (81.4\%) and 80\% knew that Hepatitis $\mathrm{B}$ vaccine protect against $\mathrm{HBV}$ infection. However, only $47.1 \%$ of them knew that $\mathrm{HBV}$ is more contagious than $\mathrm{HCV}$ and HIV, and $35.7 \%$ knew that HIV is not spread by either shaking hands or sharing same food utensils.

To facilitate comparison of the level of knowledge among the study group, the overall score of correct answers (maximum of 6) were categorized into either above average ( $\geq 60 \%$ of correct answers) or below average $(<60 \%)$.

Figure 6 illustrates that the majority of the respondents $(80.4 \%)$ achieved above average score. Table 6 shows that a significantly higher proportion of physicians $(91.3 \%)$ achieved above average score if compared to both lab technicians $(72.2 \%)$ and nurses $(76.3 \%) \mathrm{p}<0.05$. On the other side, while the percentages of those who had above 
average scores were higher among males (83.7\%), those aged $41+$ years $(84.6 \%)$, working in Ohud hospital $(88.7 \%)$, had experience 6-9 years $(88 \%)$ and those who had not been exposed to stick injury, however, these differences are not statistically significant $\mathrm{p}>0.05$.

Table 5. Knowledge of the respondents about stick injury and risks of infection $(n=219)$

\begin{tabular}{lrr}
\hline Items (correct answers) & $\begin{array}{c}\text { Correct } \\
\text { answers }\end{array}$ & $\begin{array}{c}\text { \% } \\
\text { The universal precaution decrease the risk of needle stick injuries? (yes) }\end{array}$ \\
$\begin{array}{l}\text { Needle stick injuries are preventable? (yes) } \\
\text { The biggest reduction in transmission of blood-borne infections through unsafe injections can be } \\
\text { achieved through eliminating unnecessary injections? (yes) }\end{array}$ & 60 \\
Hepatitis B vaccine prevent HBV infection? (yes) & 56 & 81.4 \\
Which is the most contagious: (HBV) & 33 & 80.0 \\
HIV is not spread by: (shaking hands and using same food utensils) & 25 & 47.1 \\
\hline
\end{tabular}

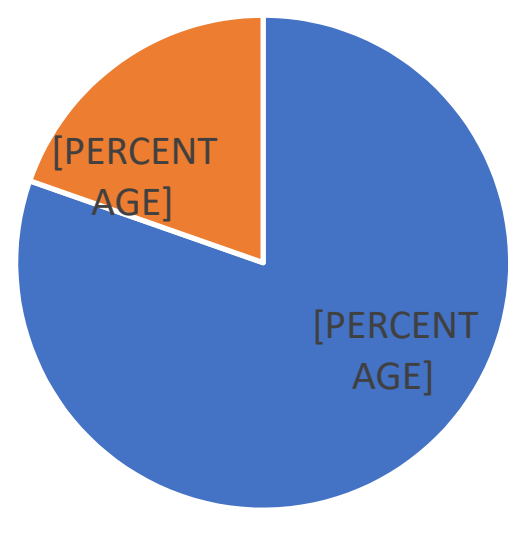

- Above average $=$ Below average

Figure 6. Level of knowledge about stick injury and risks of infection

Table 6. Level of knowledge about brick injury and risks of infection according to characteristics of the study group

\begin{tabular}{|c|c|c|c|c|c|c|c|}
\hline \multirow{3}{*}{ Characteristics } & & \multicolumn{4}{|c|}{ Level of knowledge } & \multirow{3}{*}{$X^{2}$} & \multirow{3}{*}{$\mathbf{p}$} \\
\hline & & \multicolumn{2}{|c|}{ Above average } & \multicolumn{2}{|c|}{$\begin{array}{l}\text { Below } \\
\text { average }\end{array}$} & & \\
\hline & & No & $\%$ & No & $\%$ & & \\
\hline \multirow{2}{*}{ Gender } & Male & 87 & $83.7 \%$ & 17 & $16.3 \%$ & \multirow{2}{*}{1.357} & \multirow{2}{*}{0.244} \\
\hline & Female & 89 & $77.4 \%$ & 26 & $22.6 \%$ & & \\
\hline \multirow{3}{*}{ Age group: } & 20-30 years & 91 & $80.5 \%$ & 22 & $19.5 \%$ & \multirow{3}{*}{0.432} & \multirow{3}{*}{0.806} \\
\hline & $31-40$ years & 63 & $78.8 \%$ & 17 & $21.2 \%$ & & \\
\hline & $41+$ years & 22 & $84.6 \%$ & 4 & $15.4 \%$ & & \\
\hline \multirow{3}{*}{$J o b$} & Physician & 63 & $91.3 \%$ & 6 & $8.7 \%$ & \multirow{3}{*}{7.930} & \multirow{3}{*}{$0.019 * *$} \\
\hline & Laboratory technician & 26 & $72.2 \%$ & 10 & $27.8 \%$ & & \\
\hline & Nurse & 87 & $76.3 \%$ & 27 & $23.7 \%$ & & \\
\hline
\end{tabular}




\begin{tabular}{llllllll}
\hline \multirow{2}{*}{ Place of work } & Almeqat hospital & 41 & $74.5 \%$ & 14 & $25.5 \%$ & & \\
& MCH hospital & 80 & $78.4 \%$ & 22 & $21.6 \%$ & 4.158 & 0.125 \\
& Ohud hospital & 55 & $88.7 \%$ & 7 & $11.3 \%$ & & \\
\hline \multirow{3}{*}{ Experience } & $<2$ years & 65 & $85.5 \%$ & 11 & $14.5 \%$ & & \\
& $2-5$ years & 46 & $75.4 \%$ & 15 & $24.6 \%$ & 4.032 & 0.258 \\
& $6-9$ years & 22 & $88.0 \%$ & 3 & $12.0 \%$ & & \\
\hline \multirow{2}{*}{ Exposure to stick injury } & 10+ years & 43 & $75.4 \%$ & 14 & $24.6 \%$ & & \\
& Yes & 52 & $74.3 \%$ & 18 & $25.7 \%$ & \multirow{2}{*}{2.410} & \multirow{2}{*}{0.121} \\
\hline
\end{tabular}

\section{Discussion}

Needle stick injuries (NSI) are accidental skin penetrations caused by sharp instruments in HCWs, with a high risk of occupational transmission of blood-borne pathogens. Because of the complexity and consequences of reporting, the incidence of NSI is expected to be higher than currently reported; thus, a low injury rate should not be interpreted as a non-existent problem. (Muralidhar et al., 2010) According to the Centers for Disease Control (CDC), more than 35 million health care workers are at risk of percutaneous injuries with contaminated sharp objects every year, , and 600,000 to one million needle stick injuries are estimated to occur each year. (Prüss-Üstün, Rapiti, \& Hutin, 2005) Unfortunately, approximately half of these needle stick injuries go unreported. (Center for Disease Control, 2008) The current study was conducted to determine the occurrence of NSI among health care workers (HCWs) in three main hospitals at Al Madinah Al Munawara in Saudi Arabia, and to determine the causal factors as well as their knowledge about NSI.

Nurses comprised nearly half of the participants, with the remainder being either physicians $(31.5 \%)$ or lab technicians (16.4\%). One-third of them (32\%) reported that they had been injured by a needle stick at work. These findings are similar to those reported in Ethiopia, where 30.1 percent of health-care workers were injured by needles within a year. (Mideksa \& Feyera, 2014) Conversely, a much higher incidence was discovered in North India, where 73 (68.2 percent ) HCWs reported needle stick injuries. (Ashat, Bhatia, Puri, Thakare, \& Koushal, 2011) Moreover, in a university hospital in Jamaica, where more than three-quarters of medical doctors (78 percent ) and two-thirds of nurses (64 percent ) experienced NSIs. (Vaz, McGrowder, Crawford, Alexander-Lindo, \& Irving, 2010) These differences could be attributed to differences in the strength of the regulatory rules and instructions followed in these hospitals, as well as the degree of compliance of the health staff with the precautionary standards adopted in different places.

Nurses were found to be significantly more likely to have stick injury than physicians or lab technicians; which accords what had been reported previously in Saudi Arabia, where data about needle stick and sharp-object Injury were compiled from 21 facilities in 2012. According to this report, nurses were the primary injured staff, totaling $66.4 \%$, as compared to $7.8 \%$ of physicians. (Hashmi et al., 2012) Also in USA, the majority of needle stick injuries occurred in nurses; the authors argued that because nurses have more patient contact and use needles more frequently than physicians, it is not surprising that nurses have a higher incidence of stick injuries. (Alvarado-Ramy et al., 2003) Furthermore, Ilhan (2006) stated that the long working hours typical of nurses' jobs are significantly associated with the risk of needle stick injury. (Ilhan, Durukan, Aras, Türkçüoğlu, \& Aygün, 2006)

Almost one half of the reported needle stick in our study (52.9\%) were blood stained, unfortunately, the viral status of the patients from whom the blood in contact was unknown, and one patient was known as being positive for HBsAg, and two patients (2.9\%) were HIV positive. In another study, while up to twenty blood borne pathogens (BBPs) can be transmitted by accidental injury, the most potentially life threatening are Human Immunodeficiency Virus (HIV), hepatitis B virus (HBV), and hepatitis C virus (HCV). (Zafar et al., 2009) According to the WHO (2005), exposure to sharps in the workplace accounts for $40 \%$ of HBV and HCV infection and $2 \%-3 \%$ of HIV infections among HCWs. (Prüss-Üstün et al., 2005) Following NSI, the risk of infection transmission from infected patients to $\mathrm{HCW}$ is $3-10 \%$ for hepatitis $\mathrm{B}, 3 \%$ for hepatitis $\mathrm{C}$, and $0.3 \%$ for HIV. (Wilburn \& Eijkemans, 2004)

Only $58.6 \%$ of the injured health workers in our study informed their manager/ head of department and reported the occupational health department, which means that almost one half of the incidents passed unreported. 
According to another study, there are many reasons why HCWs do not report sharp injuries; first, they may lack adequate information about reporting procedure, or the extra paperwork and time involved in follow-up following reporting. Secondly, is that they may perceive that the injuries or the source patients are low risks, lastly, they may fear losing their job if known to have certain diseases. (Haiduven et al., 1999)

The main purposes and activities for using the sharp tools or instruments which resulted in brick injuries in the current study; were drawing blood sample, injection and suturing, and the main activities were while suturing, recapping, cannulation, venipuncture and cleaning, while injuries during disposal were the least. Similar findings were reported in India, where the most common clinical activity to cause the NSI was blood withdrawal, followed by suturing and vaccination, and the practice of recapping needles after use was still prevalent among HCWs. (Muralidhar et al., 2010) Our reported main domains for activities and practices resulted in NSI accord the pattern of the risk of exposure to NSI in developed rather than the developing countries, where in the later, there is an increase in the incidence of NSIs due to improper disposal of syringes and needles. (Chowdhury et al., 2011)

Being the dominant hand, most of the injuries occurred in the right hand, with penetration of the gloves in one quarter of the cases and a higher percentage (41.4\%) had bleeding following injury. In Najran, Saudi Arabia, Hashim et al. (2012) found that the injuries primarily occur to the hands of the staff. $68.3 \%$ of sharps penetrated when the staff wore a single pair of gloves, and only $4.8 \%$ wore a double pair of gloves, which may have reduced the overall penetration of the sharps, that emphasizes the utmost importance of wearing double pair of gloves while using sharp tools in risky medical practices. (Hashmi et al., 2012) According to the CDC instructions for how to behave after exposure to needle sticks, they recommended that the site should be washed immediately and thoroughly with soap and water. (Center for Disease Control, 2021) In our study, almost all injured personnel (97.1\%) cleaned the injury site immediately and thoroughly. Different modules of cleaning were enlisted in a systematic review, they reported washing the site of injury with surgical spirit and promoting active bleeding at the site of injury in addition to washing the wound with soap and running water. (Gambhir, Gill, Kapoor, Singh, \& Singh, 2013) On the same context, another study addressed that the most common action following exposure to needle stick injury in a tertiary hospital in India was cleaning the site of injury with spirit. (Ashat et al., 2011)

Almost twenty diseases can be transmitted by NSI including HBV, HCV and HIV; vaccination is available only for HBV. (Makade, Bhawnani, Verma, \& Dengani, 2017) In the 1970s, the risk of acquiring HBV was 10 times greater in HCWs than in the general population; this significantly decline is due, in part, to deliberate vaccination campaign targeting HCWs. (Kuhar et al., 2013) In our study, (10\%) of the injured personnel were not immunized at all and (18.6\%) were partially immunized against hepatitis B at the time of injury, that put them at potential risk of acquiring HBV (Singhal et al., 2009).

In terms of respondents' knowledge of the risks and hazards of NSI, the majority of the respondents $(80.4 \%)$ scored above average score; which is similar to what had been found in tertiary hospital in India. (Makade et al., 2017) Although the majority (80\%) knew that, Hepatitis B vaccine protects against HBV infection; only $47.1 \%$ knew that $\mathrm{HBV}$ is more contagious than HCV and HIV, and $35.7 \%$ knew that HIV is not spread by either shaking hands or sharing same food utensils; which indicate critical level of knowledge about these serious infectious diseases. Physicians were found to have a significantly higher level of knowledge about the risks and hazards of NSI than nurses and technicians, which corresponds to what has been reported in the UK, (Stein, Makarawo, \& Ahmad, 2003) This could be explained by the physicians' relatively rich theoretical background, characterizing didactic teaching of the physicians than other medical staff.

\section{Conclusion and Recommendations}

Occupational needle stick injuries are fairly common among health care workers at Al Madinah Al Munawara's governmental hospitals. The majority of these injuries were superficial in the right hand, with needles containing blood stained fluids in half of the cases; they mostly occurred while drawing blood samples, injection, suturing, recapping, cannulation, and venipuncture. Almost a quarter of the injured personnel were either unimmunized or only partially immunized, and only half of these injuries were reported. The risk of NSI is significantly higher in nurses than in physicians and lab technicians, and physicians' knowledge of NSI risks and precautions was significantly higher than in nurses and lab technicians.

From the findings of this study we recommend the following:

Health workers, particularly nurses, should be given on-the-job training about NSI precautions when using sharp tools in their daily practice. In order to familiarize health workers with needle stick injuries, instructions and guidelines should be displayed in various sections of the hospital. The reporting system for NSI and confidentiality issues should be validated in order to encourage health workers to report injuries as soon as they occur. Each health 
worker's immunization status should be checked on a regular basis for completeness and missed doses should be administered and recorded in the employee's file.

\section{Competing Interests Statement}

The authors declare that there are no competing or potential conflicts of interest.

\section{References}

Alvarado-Ramy, F., Beltrami, E. M., Short, L. J., Srivastava, P. U., Henry, K., Mendelson, M., ... Chamberland, M. E. (2003). A Comprehensive Approach to Percutaneous Injury Prevention During Phlebotomy: Results of a Multicenter Study, 1993-1995. Infection Control \& Hospital Epidemiology, 24(02), 97-104. https://doi.org/10.1086/502179

Ashat, M., Bhatia, V., Puri, S., Thakare, M., \& Koushal, V. (2011). Needle stick injury and HIV risk among health care workers in North India. Indian Journal of Medical Sciences, 65(9), 371-378. https://doi.org/10.4103/0019-5359.108947

Bouya, S., Balouchi, A., Rafiemanesh, H., Amirshahi, M., Dastres, M., Moghadam, M. P., ... Daley, K. A. (2020). Global prevalence and device related causes of needle stick injuries among health care workers: A systematic review and meta-analysis. Annals of Global Health. Ubiquity Press. https://doi.org/10.5334/aogh.2698

Center for Disease Control. (2008). Workbook for Designing, Implementing, and Evaluating a Sharps Injury Prevention Program. Cdc, VI, 1-168.

Center for Disease Control. (2021). CDC - Bloodborne Infectious Diseases - surveillance - NIOSH Workplace Safety and Health Topic. www.cdc.gov. Retrieved from https://www.cdc.gov/niosh/topics/bbp/default.html

Chowdhury, A. K. A., Roy, T., Faroque, A., Bachar, S. C., Asaduzzaman, M., Nasrin, N., ... Anderson, C. (2011). A comprehensive situation assessment of injection practices in primary health care hospitals in Bangladesh. BMC Public Health, 11(1), 1-13. https://doi.org/10.1186/1471-2458-11-779

Deisenhammer, S., Radon, K., Nowak, D., \& Reichert, J. (2006). Needlestick injuries during medical training. Journal of Hospital Infection, 63(3), 263-267. https://doi.org/10.1016/j.jhin.2006.01.019

Gambhir, R., Gill, S., Kapoor, V., Singh, S., \& Singh, A. (2013). Knowledge, awareness and practice regarding needle stick injuries in dental profession in India: A systematic review. Nigerian Medical Journal, 54(6), 365. https://doi.org/10.4103/0300-1652.126283

Haiduven, D. J., Simpkins, S. M., Phillips, E. S., \& Stevens, D. A. (1999). A survey of percutaneous/mucocutaneous injury reporting in a public teaching hospital. Journal of Hospital Infection, 41(2), 151-154. https://doi.org/10.1016/S0195-6701(99)90053-1

Hashmi, A., Abu, S., Reesh, A., \& Indah, L. (2012). Prevalence of Needle-stick and Sharps Injuries among Healthcare Workers, Najran, Saudi Arabia. https://doi.org/10.4172/2161-1165.1000117

Huang, S. L., Lu, Q., Fan, S. H., Zong, Z. Y., Hou, T. Y., Chen, B. Y., ... Wang, N. N. (2017). Sharp instrument injuries among hospital healthcare workers in mainland China: A cross-sectional study. BMJ Open, 7(9), 1-8. https://doi.org/10.1136/bmjopen-2017-017761

Ilhan, M. N., Durukan, E., Aras, E., Türkçüoğlu, S., \& Aygün, R. (2006). Long working hours increase the risk of sharp and needlestick injury in nurses: The need for new policy implication. Journal of Advanced Nursing, 56(5), 563-568. https://doi.org/10.1111/j.1365-2648.2006.04041.x

Kelen, G. D., Fritz, S., Qaqish, B., Brookmeyer, R., Baker, J. L., Kline, R. L., ... Quinn, T. C. (1988). Unrecognized Human Immunodeficiency Virus Infection in Emergency Department Patients. New England Journal of Medicine, 318(25), 1645-1650. https://doi.org/10.1056/nejm198806233182503

Khabour, O. F., Al Ali, K. H., \& Mahallawi, W. H. (2018). Occupational infection and needle stick injury among clinical laboratory workers in Al-Madinah city, Saudi Arabia. Journal of Occupational Medicine and Toxicology, 13(1), 1-7. https://doi.org/10.1186/s12995-018-0198-5

Kuhar, D. T., Henderson, D. K., Struble, K. A., Heneine, W., Thomas, V., Cheever, L. W., ... Panlilio, A. L. (2013). Updated US Public Health Service Guidelines for the Management of Occupational Exposures to Human Immunodeficiency Virus and Recommendations for Postexposure Prophylaxis. Infection Control \& Hospital Epidemiology, 34(9), 875-892. https://doi.org/10.1086/672271

Makade, K. G., Bhawnani, D., Verma, N., \& Dengani, M. (2017). Knowledge and response of health care workers after needle - stick injury in a tertiary care hospital setting in tribal Rajnandgaon, Chhattisgarh, India. 
International Journal of Research in Medical Sciences, $5(3), \quad 816$. https://doi.org/10.18203/2320-6012.ijrms20170534

Mideksa, L., \& Feyera, T. (2014). Needle-Stick Injuries and Contributing Factors among Healthcare Workers in Public Health Facilities in Jigjiga Zone, Eastern Ethiopia. undefined.

Muralidhar, S., Singh, P. K., Jain, R. K., Malhotra, M., \& Bala, M. (2010). Needle stick injuries among health care workers in a tertiary care hospital of India. Indian Journal of Medical Research, 131(3), 405-410. Repéré à https://pubmed.ncbi.nlm.nih.gov/20418554/

Prüss-Üstün, A., Rapiti, E., \& Hutin, Y. (2005). Estimation of the global burden of disease attributable to contaminated sharps injuries among health-care workers. American Journal of Industrial Medicine, 48(6), 482-490. https://doi.org/10.1002/ajim.20230

Simonsen, L., Kane, A., Lloyd, J., Zaffran, M., \& Kane, M. (1999). Unsafe injections in the developing world and transmission of bloodborne pathogens: A review. Bulletin of the World Health Organization. Repéré à https://pubmed.ncbi.nlm.nih.gov/10593026/

Singhal, V., Bora, D., \& Singh, S. (2009). Hepatitis B in Health Care Workers: Indian Scenario. Journal of Laboratory Physicians, 1(02), 041-048. https://doi.org/10.4103/0974-2727.59697

Stein, A. D., Makarawo, T. P., \& Ahmad, M. F. R. (2003). A survey of doctors' and nurses' knowledge, attitudes and compliance with infection control guidelines in Birmingham teaching hospitals. Journal of Hospital Infection, 54(1), 68-73. https://doi.org/10.1016/S0195-6701(03)00074-4

Tawil, D. (2016). Knowledge and prevalence of needle stick injuries among nurses working in hemodialysis units in Al jouf region, Saudi Arabia . IOSR Journal of Nursing and Health Science (IOSR-JNHS), 5(6), 13-19.

Vaz, K., McGrowder, D., Crawford, T., Alexander-Lindo, R., \& Irving, R. (2010). Prevalence of injuries and reporting of accidents among health care workers at the University Hospital of the West Indies. International Journal of Occupational Medicine and Environmental Health, 23(2), 133-143. https://doi.org/10.2478/v10001-010-0016-5

Wilburn, S. Q., \& Eijkemans, G. (2004). Preventing needlestick injuries among healthcare workers: A WHO-ICN collaboration. International Journal of Occupational and Environmental Health. Abel Publications Services Inc. https://doi.org/10.1179/oeh.2004.10.4.451

Zafar, A., Habib, F., Hadwani, R., Ejaz, M., Khowaja, K., Khowaja, R., \& Irfan, S. (2009). Impact of infection control activities on the rate of needle stick injuries at a tertiary care hospital of Pakistan over a period of six years: an observational study. https://doi.org/10.1186/1471-2334-9-78

\section{Copyrights}

Copyright for this article is retained by the author(s), with first publication rights granted to the journal.

This is an open-access article distributed under the terms and conditions of the Creative Commons Attribution license (http://creativecommons.org/licenses/by/4.0/). 